\title{
Analysis of Tetracycline Antibiotics Using HPLC with Pulsed Amperometric Detection
}

\author{
Thiraporn Charoenraks, ${ }^{*}$ Suchada Chuanuwatanakul, * Kensuke Honda, *** \\ Yoko Yamaguchi, ${ }^{* *}$ and Orawon ChaILAPAKuL ${ }^{* \dagger}$ \\ *Department of Chemistry, Faculty of Science, Chulalongkorn University, Patumwan, \\ Bangkok 10330, Thailand \\ **Department of Chemistry and Earth Sciences, Faculty of Science, Yamaguchi University, \\ 1677-1, Yoshida, Yamaguchi-shi, Yamaguchi 753-8512, Japan
}

\begin{abstract}
The analysis of tetracycline, oxytetracyline, chlortetracycline and doxycycline by high-performance liquid chromatography with pulsed amperometric detection using an anodized boron-doped diamond thin film (BDD) electrode is originally reported. The analyses were carried out using the mobile phase, phosphate buffer $(0.01 \mathrm{M}, \mathrm{pH}$ 2.5)-acetonitrile $(80: 20 ; \mathrm{v} / \mathrm{v})$, on a $\mathrm{C}_{18}$ column $(250 \times 4.6 \mathrm{~mm}$ i.d., $5 \mu \mathrm{m})$ at a flow rate of $1.0 \mathrm{~mL} / \mathrm{min}$. The optimal PAD waveform parameters at the anodized BDD were $1.5 \mathrm{~V}$ (versus $\mathrm{Ag} / \mathrm{AgCl})$ detection potential $\left(E_{\mathrm{det}}\right)$ for $290 \mathrm{~ms}(200 \mathrm{~ms}$ delay time and $90 \mathrm{~ms}$ integration time), $2.0 \mathrm{~V}$ (versus $\mathrm{Ag} / \mathrm{AgCl})$ oxidation potential $\left(E_{\mathrm{oxd}}\right)$ for $200 \mathrm{~ms}$ oxidation time $\left(t_{\mathrm{oxd}}\right)$ and $0.4 \mathrm{~V}$ (versus $\mathrm{Ag} / \mathrm{AgCl}$ ) reduction potential $\left(E_{\mathrm{red}}\right)$ for $200 \mathrm{~ms}$ reduction time $\left(t_{\mathrm{red}}\right)$. The proposed method showed the simultaneous determination of tetracycline, oxytetracyline, chlortetracycline and doxycycline with a linear range of 0.1 $100 \mu \mathrm{g} / \mathrm{mL}$, detection limits of $0.05-0.1 \mu \mathrm{g} / \mathrm{mL}$ and recoveries of $70.8-96.0 \%$. The application of this method to real samples was demonstrated and validated using a shrimp sample.
\end{abstract}

(Received October 4, 2004; Accepted November 10, 2004)

\section{Introduction}

Tetracyclines are broad-spectrum antibiotics, such as tetracycline (TC), chlortetracycline (CTC), doxycycline (DTC), and oxytetracycline (OTC). These compounds are commonly used in veterinary medicine to prevent diseases and as an additive in animal foods to promote growth. ${ }^{1-3}$ Tetracyclines are widely used in diary cattle, poultry and shrimp. ${ }^{3,4}$ To ensure food safety to consumers, EU, FAO/WHO and FDA have set safe levels for residue tetracyclines in milk $(0.1 \mathrm{mg} / \mathrm{kg}),{ }^{3}$ liver $(0.3 \mathrm{mg} / \mathrm{kg})$, egg $(0.2 \mathrm{mg} / \mathrm{kg})$, and muscle tissue $(0.1 \mathrm{mg} / \mathrm{kg}){ }^{5}$ Thus, a sensitive and reproducible method for the determination of tetracyclines at residual levels is urgently needed.

Several analytical methods have been reported for the determination of tetracylines in various samples, such as milk, ${ }^{1-3,6-9}$ shrimp, ${ }^{1,4}$ animal feeds, ${ }^{5,10}$ animal tissues ${ }^{11-13}$ and pharmaceutical formulations ${ }^{14,15}$ based on thin-layer chromatography, ${ }^{10}$ capillary electrophoresis, ${ }^{16,17}$ and high performance liquid chromatography (HPLC). ${ }^{6-8,11-14}$ HPLC is a common method that separates tetracyclines in the reversephase mode with different detection methods, such as spectrophotometry, ${ }^{12,13}$ fluorometry, ${ }^{18,19}$ mass spectrometry, ${ }^{20,21}$ and electrochemistry. ${ }^{14,15}$

Electrochemical methods are more interesting than the other methods due to simplicity, no more reagents for derivatization, low cost, and less time analysis. Moreover, electrochemical detection offers better sensitivity and detection limits for non-

$\dagger$ To whom correspondence should be addressed.

E-mail: corawon@chula.ac.th aromatic compounds when compared with UV detection. Many studies have been developed for the determination of tetracycline antibiotics using electrochemical detection, such as polarography, ${ }^{22,23}$ potentiometry ${ }^{24}$ and amperometry. ${ }^{14,15}$ In 1997, Kazemifard and Moore ${ }^{14}$ reported the use of amperometric detection at a glassy carbon electrode for the detection of tetracyclines, following liquid chromatography. Although amperometric detection provided high sensitivity, the major disadvantage is the deposition of detection products or impurities on the electrode surface. In 2003, Palaharn et al. ${ }^{15}$ reported the use of pulsed amperometric detection (PAD) at a gold electrode for analysis of tetracycline and applied to a flowinjection system. The advantage of PAD offers cleaning and reactivating the electrode surface after a measuring cycle without mechanical polishing. The PAD technique typically comprises the three steps shown in Fig. 1. The three steps of the

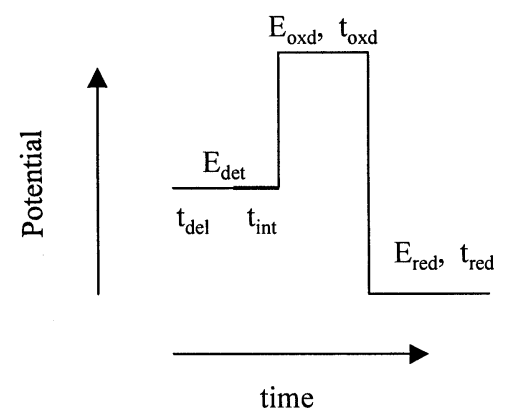

Fig. 1 Typical PAD waveform 
PAD technique require the following: (a) the analytes are oxidized at the detection potential $\left(E_{\mathrm{det}}\right)$ during a detection period consisting of delay time $\left(t_{\mathrm{del}}\right)$ and integration time $\left(t_{\mathrm{int}}\right)$; (b) the adsorbed detection products or impurities are removed from the electrode surface at the oxidation potential $\left(E_{\text {oxd }}\right)$ during the oxidation time $\left(t_{\mathrm{oxd}}\right)$; (c) the inert oxide film is cathodically dissolved at the reduction potential $\left(E_{\mathrm{red}}\right)$ during the reduction time $\left(t_{\text {red }}\right)$. Therefore, this method is recommended as an alternative method for sensitive detection. From many reviewed reports, it is interesting to combine liquid chromatography and the PAD technique with an anodized boron-doped diamond electrode to separate and detect no significant UV absorbing chromophore and electroactive compounds. . $^{25-28}$

The boron-doped diamond thin film (BDD) electrodes have many advantages for electroanalysis applications, due to their unique electrochemical properties ${ }^{29}$ which include a wide electrochemical potential window in aqueous solutions, a very low background current, and great electrochemical stability. ${ }^{29-31}$ Recently, it was found that BDD electrodes pretreated by electrochemical oxidation exhibit well-defined irreversible cyclic voltammograms for the oxidation of tetracycline antibiotics with the highest current signals compared to the asdeposited BDD and glassy carbon electrodes. ${ }^{32}$ These anodized BDD electrodes retain the excellent properties of the asdeposited diamond electrode. Various environmental, biological and clinical compounds were investigated using anodized BDD electrodes. ${ }^{30-33}$

To obtain higher sensitivity, the anodized BDD has been used as the working electrode for pulsed amperometric detection coupled with HPLC. Finally, we applied the proposed method to determine tetracycline antibiotics in shrimps.

\section{Experimental}

\section{Chemicals and reagents}

Tetracycline-HCl (TC), oxytetracycline-HCl (OTC), chlortetracycline- $\mathrm{HCl}$ (CTC), and doxycycline- $\mathrm{HCl}$ (DTC) were obtained from Sigma-Aldrich. Acetonitrile and methanol (Merck) were of HPLC grade. Disodium hydrogenphosphate (BDH), citric acid monohydrate (J. T. Baker), diaminetetraacetic acid disodium salt (Fluka) and orthophosphoric acid (J. T. Baker) were of analytical grade. Doubly distilled water was purified using a Milli-Q system (Millipore, Bedford, MA, USA). Solid-phase extraction (SPE) C18-E cartridges $(500 \mathrm{mg}, 6 \mathrm{~mL})$ were obtained from Phenomenex (USA).

A phosphate buffer solution of $\mathrm{pH} 2.5$ was prepared daily by mixing $0.01 \mathrm{M} \mathrm{H}_{3} \mathrm{PO}_{4}+0.1 \mathrm{M} \mathrm{Na}_{2} \mathrm{HPO}_{4}$ (a few drops to adjust the $\mathrm{pH}$ ). The mobile phase for the HPLC condition consisted of $20 \%$ acetonitrile containing the phosphate buffer $(0.01 \mathrm{M}, \mathrm{pH}$ 2.5).

A $\mathrm{Na}_{2}$ EDTA-McIlvaine buffer solution ( $\mathrm{pH} \mathrm{4}$ ) was prepared by dissolving $15 \mathrm{~g}$ of disodium hydrogen phosphate dihydrtae, $13 \mathrm{~g}$ of citric acid monohydrate and $3.72 \mathrm{~g}$ of EDTA in water and diluting to 1 liter.

Stock solutions $(1000 \mu \mathrm{g} / \mathrm{mL})$ of TC, OTC, CTC and DTC were prepared by dissolving $10 \mathrm{mg}$ in $10 \mathrm{~mL}$ of the mobile phase. Working standard solutions were prepared by diluting the stock solution with the mobile phase. All of the solutions were protected from exposure to light and stored in a refrigerator.

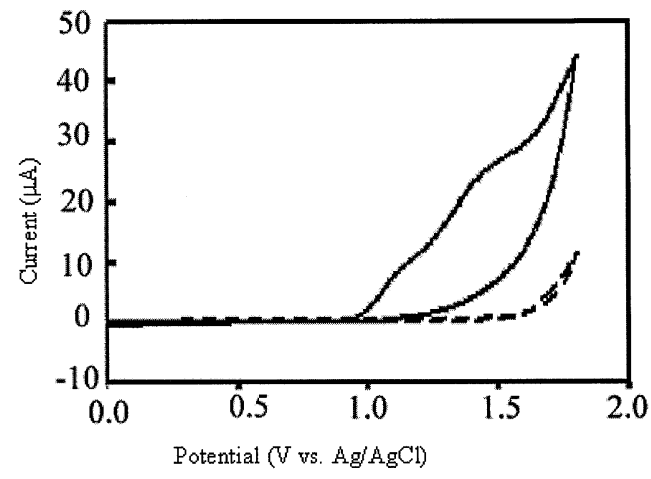

Fig. 2 Cyclic voltammograms for $1 \mathrm{mM}$ tetracycline in $0.01 \mathrm{M}$ phosphate buffer ( $\mathrm{pH}$ 2.5) at an anodized BDD electrode. The sweep rate was $100 \mathrm{mV} / \mathrm{s}$. The background voltammograms are also shown in the figure by the dotted line.

\section{Sample preparation}

The shells, fins and tails of shrimp were removed and ground in a conventional meat grinder. The ground shrimp was stored at below $-10^{\circ} \mathrm{C}$ until analysis. After a $5.0 \mathrm{~g}$ portion of ground shrimp was placed in a $50 \mathrm{~mL}$ centrifuge tube, $25 \mathrm{~mL}$ of $\mathrm{Na}_{2}$ EDTA-McIlvaine buffer ( $\mathrm{pH} 4$ ) was added, and then the mixture was centrifuged at 366.5 radian per second for $20 \mathrm{~min}$. The supernatant was loaded into a SPE cartridge, previously activated with $10 \mathrm{~mL}$ of methanol and $10 \mathrm{~mL}$ of Milli-Q water. After sample loading, the SPE cartridge was washed with 10 $\mathrm{mL}$ of Milli-Q water, and finally tetracyclines were eluted by 10 $\mathrm{mL}$ of methanol. The solvent was removed under a nitrogen stream. The residues were filtered with a $0.45 \mu \mathrm{m}$ PTFE filter. Then, $20 \mu \mathrm{L}$ of an aliquot was injected to the HPLC system.

\section{Apparatus}

A Waters Model 510 solvent delivery system was used (Waters Associates Inc, Milford, MA, USA) with a Rheodyne No. 7125 injector system and a $20 \mu \mathrm{L}$ sample loop. The column was Inertsil-ODS3 C18 $(5 \mu \mathrm{m}, 4.6 \mathrm{~mm} \times 25 \mathrm{~cm}$; GL Science). The electrochemical detector was applied using a computercontrolled potentiostat (Autolab PGSTAT 30, Metrohm, Switzerland).

A thin-layer electrochemical cell was composed of a $0.36 \mathrm{~cm}^{2}$ area boron-doped diamond electrode as the working electrode, a $\mathrm{Pt}$ wire as the counter electrode, and $\mathrm{Ag} / \mathrm{AgCl}$ as the reference electrode.

The as-deposited BDD electrodes used in this work were obtained from Associate Prof. Kensuke Honda. This electrode was a monopolar one-side coating. An anodized BDD electrode was prepared by treating an as-deposited BDD electrode in a 0.1 $\mathrm{M} \mathrm{KOH}$ solution. A potential was applied between 0 to $2 \mathrm{~V}$ versus $\mathrm{Ag} / \mathrm{AgCl}$ at a scan rate of $10 \mathrm{mV} / \mathrm{s}$ using cyclic voltammetry for $30 \mathrm{~min}$. The anodized BDD electrode was also rinsed with ultrapure water before use.

The separations were performed using phosphate buffer $(0.01$ $\mathrm{M}, \mathrm{pH} 2.5)$-acetonitrile $(80: 20, \mathrm{v} / \mathrm{v})$ as the mobile phase at a flow-rate of $1.0 \mathrm{~mL} / \mathrm{min}$ at ambient temperature.

\section{Results and Discussion}

Voltammetric study

The cyclic voltammetric (I-E) responses for a solution containing $1 \mathrm{mM}$ tetracycline in a phosphate buffer $(0.01 \mathrm{M}, \mathrm{pH}$ 2.5) together with the corresponding background 


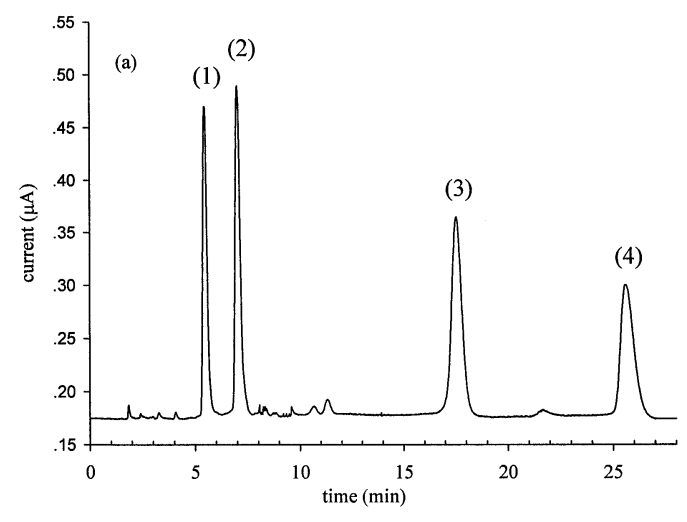

Fig. 3 HPLC-PAD chromatograms of a standard mixture containing $50 \mathrm{ppm}$ concentrations of (1) oxytetracycline, (2) tetracycline, (3) chlortetracycline, and (4) doxycycline at the anodized BDD electrodes. The mobile phase was $20 \%$ acetonitrile in phosphate buffer $(0.01 \mathrm{M}, \mathrm{pH} 2.5)$. The injection volume was $20 \mu \mathrm{L}$, and the flow rate was $1 \mathrm{~mL} / \mathrm{min}$.

voltammograms at the anodized BDD electrode are shown in Fig. 2. The results obtained from the other antibiotics, i.e., chlortetracycline, oxytetracycline and doxycycline, were analogous to the results shown for tetracycline in Fig. 2. At the anodized BDD, the oxidation of tetracycline occurred in the region of ca. +1.2 to $+1.6 \mathrm{~V}$ versus $\mathrm{Ag} / \mathrm{AgCl}$, and a cathodic peak was not observed on the negative scan in the region of $c a$. +0.8 to $0.0 \mathrm{~V}$ versus $\mathrm{Ag} / \mathrm{AgCl}$.

\section{PAD waveform optimization}

The PAD waveform used in this experiment is described in Fig. 1. The advantage of PAD is mainly realized, because of the multi-step potential waveform that continuously regenerates the condition responsible for a detection measurement, together with cleaning and reactivation at the working electrode. $E_{\mathrm{det}}$ is the detection potential at which tetracyclines are oxidized during the time period $\left(t_{\mathrm{det}}=t_{\mathrm{del}}+t_{\mathrm{int}}\right)$, and the electrode current is sampled by electronic integration over the investigation time $\left(t_{\text {int }}\right)$ following the delay time $\left(t_{\mathrm{del}}\right)$ to decrease the charging current. $E_{\text {oxd }}$ is a positive cleaning potential in order to remove any oxidizable impurities on the electrode surface for the oxidation time $\left(t_{\mathrm{oxd}}\right)$ following $E_{\mathrm{det}}$. Finally, $E_{\mathrm{red}}$ is a negative reactivating potential for the reduction of an inert oxide product on the electrode surface during the reduction time $\left(t_{\text {red }}\right)$ following $E_{\text {red. }}$. The optimum conditions were obtained by the injection of a standard solution under the liquid chromatographic conditions.

The potential range used for $E_{\text {det }}$ optimization was chosen from the potential region in the cyclic voltammogram (Fig. 2), at which the oxidation of tetracyclines occurred. $E_{\operatorname{det}}$ was varied from +1.2 to $+1.5 \mathrm{~V}$ versus $\mathrm{Ag} / \mathrm{AgCl}$ at the anodized $\mathrm{BDD}$ electrode in intervals of $500 \mathrm{mV}$. From the results, the optimal detection potential for the anodized BDD was chosen to be +1.5 $\mathrm{V}$ versus $\mathrm{Ag} / \mathrm{AgCl}$. Then, the optimal $E_{\mathrm{det}}$ was kept constant to optimize the other parameters. The $t_{\text {del }}$ was varied from 100 to $900 \mathrm{~ms}$ in intervals of $100 \mathrm{~ms}$, and $t_{\mathrm{int}}$ was varied from 30 to 120 $\mathrm{ms}$ in $30 \mathrm{~ms}$ increments.

To receive reproducible signals, the electrode should be pulsed adequately at a more positive potential to remove any adsorbed species. $E_{\text {oxd }}$ optimization was varied from +1.7 to $+2.0 \mathrm{~V}$ versus $\mathrm{Ag} / \mathrm{AgCl}$ intervals of $100 \mathrm{mV}$. The variation of $t_{\text {oxd }}$ was optimized from 100 to $900 \mathrm{~ms}$. To reactivate the surface oxide at the electrode surface, it was essential that the
Table 1 Optimal PAD waveform parameters for the proposed method at the anodized BDD electrode

\begin{tabular}{lcc}
\hline & $E$ & Time $/ \mathrm{ms}$ \\
\hline Detection step & 1.5 & $200\left(t_{\text {del }}\right)$ \\
& & $90\left(t_{\text {int }}\right)$ \\
Oxidation step & 2.0 & 200 \\
Reactivation step & 0.4 & 200 \\
\hline
\end{tabular}

Table 2 Calibration characteristics of oxytetracycline, tetracycline, chlortetracycline and doxycycline for the proposed method at the anodized BDD electrode

\begin{tabular}{lccc}
\hline & Linear equation & $\begin{array}{c}\text { Regression } \\
\text { coefficient }\end{array}$ & $\begin{array}{c}\text { Limits of } \\
\text { detection/ } \\
\mu \mathrm{g} \mathrm{mL}\end{array}$ \\
\hline Oxytetracycline & $Y=73.107 X+103.74$ & 0.9950 & 0.05 \\
Tetracycline & $Y=83.015 X+388.94$ & 0.9893 & 0.05 \\
Chlortetracycline & $Y=123.48 X+228.71$ & 0.9987 & 0.1 \\
Doxycycline & $Y=71.775 X+119.53$ & 0.9982 & 0.1 \\
\hline
\end{tabular}

$E_{\text {red }}$ and $t_{\text {red }}$ be optimized. In this reactivation step, $E_{\text {red }}$ was varied in +0.1 to $+0.4 \mathrm{~V}$ versus $\mathrm{Ag} / \mathrm{AgCl}$ in intervals of $100 \mathrm{mV}$ for several values of $t_{\mathrm{red}}$ in the range 100 to $600 \mathrm{~ms}$. The optimal PAD waveform parameters for the determination of tetracyclines are given in the Table 1 .

\section{Liquid chromatography with pulsed amperometric detection}

In general, because tetracyclines are analyzed by reversedphase HPLC, the separation in this experiment was performed using a $\mathrm{C}-18$ column. The $\mathrm{pH}$ of the mobile phase was selected to be 2.5 so as to reduce the formation of isomeric analogues. Also, this $\mathrm{pH}$ gave a well-defined and high signal of cyclic voltammograms of tetracycline oxidation. In this experiment, the phosphate buffer was chosen because it could provide low background currents. No reaction between buffer and tetracyclines was observed over the potential range of interest. Therefore, phosphate buffer $(0.01 \mathrm{M}, \mathrm{pH} 2.5)$ was used to separate tetracyclines, and significantly prolonged the retention time in the presence of $20 \%$ acetonitrile. The chromatograms of a standard solution of tetracycline are presented in Fig. 3. The retention times were 5.6, 7.5, 17.5 and 26.0 for oxytetracycline, tetracycline, chlortetracycline and doxycycline, respectively. To complete the separation of oxytetracycline, tetracycline, chlortetracycline and doxycycline, it required $28 \mathrm{~min}$.

\section{Linearity and detection limit}

The current responses of tetracycline, oxytetracycline, chlortetracycline and doxycycline varied linearly with 7 standard concentrations, covering the range of $0.1-100 \mu \mathrm{g} / \mathrm{mL}$. The calibration characteristics of tetracycline, oxytetracycline, chlortetracycline and doxycycline at the anodized BDD are given in Table 2. Table 2 also gives the detection limits at the signal-to-noise ratio (3:1) for tetracyclines.

\section{Recoveries}

The recoveries of tetracycline, oxytetracycline, chlortetracycline and doxycycline were determined by injecting a blank shrimp sample spiked along with the standard samples. It can be observed from the chromatogram (Fig. 4) that the peaks due to the other components did not interfere with those 
Table 3 Recoveries of oxytetracyline, tetracycline, chlortetracycline and doxycycline in shrimp samples using the HPLC-PAD method at the anodized BDD electrode

\begin{tabular}{cccr}
\hline \multirow{2}{*}{ Spiked/ $\mu \mathrm{g} \mathrm{mL} \mathrm{mL}^{-1}$} & \multicolumn{2}{c}{ Recovery, $\%(n=3)$} \\
\cline { 2 - 4 } & Oxytetracycline & Tetracycline & Chlortetracycline \\
\hline 1.0 & $82.6-90.3$ & $83.5-93.5$ & $76.3-84.5$ \\
10.0 & $81.6-92.4$ & $85.5-96.0$ & $86.5-90.7$ \\
\hline
\end{tabular}

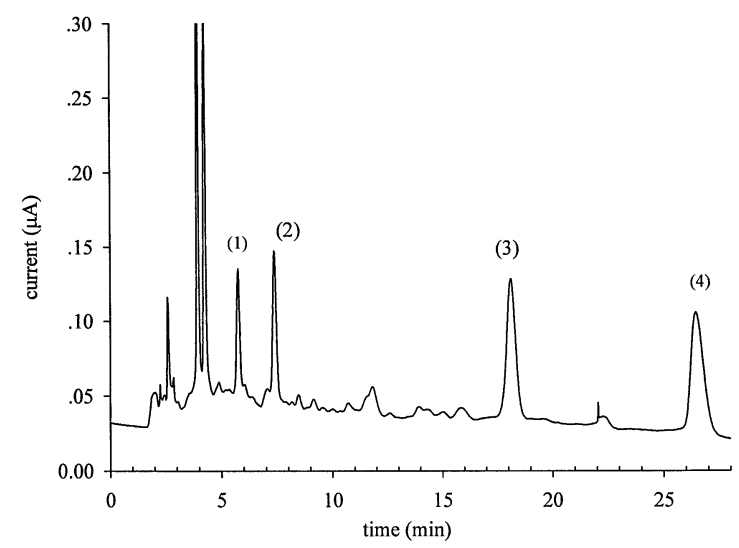

Fig. 4 HPLC-PAD chromatogram of a shrimp sample spiked with $10 \mu \mathrm{g} / \mathrm{mL}$ each of (1) oxytetracycline, (2) tetracycline, (3) chlortetracycline and (4) doxycycline at the anodized BDD electrode. The other conditions are the same as in Fig. 3.

of tetracyclines. The recoveries of tetracycline, oxytetracycline, chlortetracycline and doxycycline at two different spiked levels are summarized in Table 3.

\section{Conclusions}

We can use HPLC-pulsed amperometric detection (PAD) with an anodized boron-doped diamond electrode to determine tetracycline antibiotics. The optimized conditions were examined by varying the various potentials and times. HPLCpulsed amperometry is simple and time saving because the cleaning step occurs simultaneously during the measurement. The current signal of the anodized BDD electrode provided a high current, indicating high sensitivity of the anodized BDD electrode and the feasibility for practical use of this electrode.

HPLC-PAD at an anodized BDD electrode has been successfully applied to determine four types of tetracyclines (tetracycline, chlortetracycline, oxytetracycline and doxycycline) in shrimp samples. An experimental detection limit of $0.05-0.1 \mu \mathrm{g} / \mathrm{mL}$ was obtained. A linear dynamic range from 0.1 to $100 \mu \mathrm{g} / \mathrm{mL}$ was achieved. These results demonstrate the possibility of the practical utility of an anodized BDD electrode in pulsed amperometric detection coupled with HPLC systems to analyze a low content of tetracycline antibiotics in the other complicated samples, such as animal tissue.

\section{Acknowledgements}

This research was supported by the Ratchadaphisek Somphot Grant, Chulalongkorn University and the Thailand Research
Fund. Special thanks are extended to Associate Prof. Kensuke Honda (Yamaguchi University) for the boron-doped diamond thin film electrode used in this research.

\section{References}

1. M. C. Carson, M. A. Ngoh, and S. W. Hadley, J. Chromatogr., B, 1998, 712, 113.

2. W. A. Moats, J. Agric. Food. Chem., 2000, 48, 2244.

3. F. J. Schenck and P. S. Callery, J. Chromatogr., A, 1998, $812,99$.

4. E. A. Tendencia and L. D. de la Pena, Aquaculture, 2001, 195, 193.

5. A. D. Cooper, G. W. F. Stubbings, M. Kelly, J. A. Tarbin, W. H. H. Farrington, and G. Shearer, J. Chromatogr., A, 1998, 812, 321.

6. A. L. Cinquina, F. Longo, G. Anastasi, L. Giannetti, and R. Cozzoani, J. Chromatogr., A, 2003, 987, 227.

7. N. Furusawa, Talanta, 2003, 59, 155.

8. W. A. Moats and R. Harikkhan, J. Agric. Food. Chem., 1995, 43, 931.

9. A. L. S. Pena, C. M. Lino, and I. N. Silveira, J. AOAC Int., 1999, 82, 55.

10. N. D. Weng, S. Hua, E. Roets, and J. Hoogmartens, J. Pharm. Biomed. Anal., 2003, 33, 85.

11. W. J. Blanchflower, R. J. McCracken, A. S. Haggan, and D. G. Kennedy, J. Chromatogr., B, 1997, 692, 351.

12. J. Sokol and E. Matisova, J. Chromatogr., A, 1994, 669, 75.

13. J. R. Walsh, L. V. Walker, and J. J. Webber, J. Chromatogr., 1992, 596, 211.

14. A. G. Kazemifard and D. E. Moore, J. Pharm. Biomed. Anal., 1997, 16, 689.

15. S. Palaharn, T. Charoenraks, N. Wangfuengkanagul, K. Grudpan, and O. Chailapakul, Anal. Chim. Acta, 2003, 499, 191.

16. J. Tjornelund and S. H. Hansen, J. Chromatogr., A, 1997, 779, 235.

17. C. L. Chen and X. L. Gu, J. AOAC Int., 1995, 78, 1369.

18. S. Croubels, W. Baeyens, and C. Vanpeteghem, Anal. Chim. Acta, 1995, 303, 11.

19. D. S. Vienneau and C. G. Kindberg, J. Pharm. Biomed. Anal., 1997, 16, 111.

20. J. Zhu, D. D. Snow, D. A. Cassada, S. J. Monson, and R. F. Spalding, J. Chromatogr., A, 2001, 928, 177.

21. M. Cherlet, M. Schelkens, S. Croubels, and P. De Backer, Anal. Chim. Acta, 2003, 492, 199.

22. S. Sabharwal, K. Kishore, and P. N. Moorthy, J. Pharm. Sci., 1988, 77, 78.

23. I. G. H. Tanase, I. G. David, G. L. Radu, E. E. Iorgulescu, and V. Magearu, Analusis, 1996, 24, 281.

24. C. M. C. M. Couto, J. L. F. C. Lima, M. Conceicao, B. S. M. Montenegro, and S. Reis, J. Pharm. Biomed. Anal., 1998, $18,527$. 
25. J. Szunyog, E. Adams, E. Roets, and J. Hoogmartens, J. Pharm. Biomed. Anal., 2000, 23, 891.

26. J. Szunyog, E. Adams, K. Liekens, E. Roets, and J. Hoogmartens, J. Pharm. Biomed. Anal., 2002, 29, 213

27. E. Adams, W. Roelants, R. De Paepe, E. Roets, and J. Hoogmartens, J. Pharm. Biomed. Anal., 1998, 18, 689.

28. Y. Mo, D. Dobberpuhl, and A. K. Dash, J. Pharm. Biomed. Anal., 2003, 32, 125.

29. J. S. Xu, M. C. Granger, Q. Y. Chen, J. W. Strojek, T. E. Lister, and G. M. Swain, Anal. Chem., 1997, 69, 591A.
30. C. Terashima, T. N. Rao, B. V. Sarada, D. A. Tryk, and A. Fujishima, Anal. Chem., 2002, 74, 895.

31. T. A. Ivandini, B. V. Sarada, C. Terashima, T. N. Rao, D. A. Tryk, H. Ishiguro, Y. Kubota, and A. Fujishima, J. Chromatogr., B, 2003, 791, 63.

32. N. Wangfuengkanagul, W. Siangproh, and O. Chailapakul, Talanta, 2004, 64, 1183.

33. C. Terashima, T. N. Rao, B. V. Sarada, Y. Kubota, and A. Fujishima, Anal. Chem., 2003, 75, 1564. 